\title{
COMENTARIO EDITORIAL \\ Evolución de la relación médico-paciente: de la medicina centrada en el médico a la medicina centrada en el paciente
}

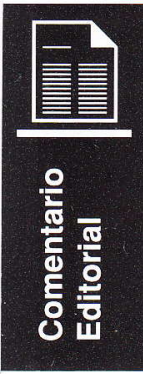

En las últimas décadas la relación médico-paciente ha evolucionado franca y positivamente en muchos aspectos. La relación médico-paciente y en particular la entrevista médica, dejaron de ser disciplinas empíricas que surgían solamente de la puesta en práctica de los conocimientos médicos adquiridos en las escuelas de medicina. Ha habido una explosión de libros y escuelas que trabajan continuamente en el conocimiento y perfeccionamiento de la relación para que el médico disponga de nuevos instrumentos que le permitan mejorar la salud de los pacientes y éstos reciban nuevos elementos con los que se puedan comunicar mejor con sus médicos

Finalmente, así como el reconocimiento de los derechos humanos ha valorado enormemente la vida de los individuos independientemente de su lengua, religión, edad, formación, etc. también ha evolucionado el reconocimiento de los derechos de los pacientes quienes ya no se limitan a recibir y obedecer sino que pueden ejercer su derecho a entender, a preguntar, a disentir y exigir y finalmente, a demandar. El ejemplo que sigue a continuación pertenece a Casell ${ }^{1}$ y es ilustrativo en este sentido:

"Durante los años treinta mi abuela consultó a un especialista por un melanoma facial. Durante la visita, cuando ella le hizo una pregunta al médico, él le palmeó la cara, diciendo: Yo hago las preguntas aquí ". Puede usted imaginar una situación semejante en nuestros días? Los melanomas pueden no haber cambiado mucho en los últimos cincuenta años pero sí la profesión médica.

En los últimos años se ha desencadenado una gran discusión sobre el rol de los médicos en la toma de decisiones, a menudo caracterizada como un conflicto entre autonomía y salud, entre los valores de los pacientes y los valores de los médicos. Hipócrates rezaba:

"...ocultar lo más que se pueda mientras se atiende al paciente... revelar nada sobre su condición actual o futura."

En un discurso de graduación de la escuela de medicina en 1871 el famoso escritor y médico norteamericano, Oliver Wendell Holmes aconsejaba:

"El derecho de su paciente a toda la verdad que usted conoce no es mayor que el derecho que él tiene a toda la medicina que hay en sus alforjas. El debería conocer solamente lo que es bueno para él... Algunos viejos médicos astutos tienen siempre algunas frases a mano para aquellos pacientes que insisten en conocer el origen de sus males sin la más mínima capacidad de entender su explicación científica. Yo encuentro muy útil en dichas ocasiones al término 'irritación medular'".

Sin duda, tanto Hipócrates como Holmes serían seriamente cuestionados actualmente, al menos en lugares donde tanto la medicina como el reconocimiento de los derechos de los pacientes, han evolucionado.

Esta evolución se ha acelerado notablemente en los últimos cuarenta años. El mismo Holmes aconsejaba evitar el término carcinoma al hablar con los pacientes. Un estudio realizado en 1961 revelaba que los médicos no se habían alejado mucho de los preceptos de Holmes: $90 \%$ de los médicos encuestados preferían no revelarle el diagnóstico a sus pacientes con cáncer2. Sin embargo, en 1979, esta actitud se había revertido prácticamente en su totalidad y $97 \%$ de los médicos encuestados prefería revelar el diagnóstico a sus pacientes. Cabe aclarar que estas cifras pertenecen a la literatura extranjera y corresponden a poblaciones anglosajonas. Sería bueno conocer que evolución ha habido en los profesionales de la salud que trabajan y pertenecen a culturas latinas.

Respecto de la magnitud del cambio, dos opiniones lo simbolizan:

"Basta de pensar en términos de adherencia, reconozcamos el derecho de los pacientes a tomar sus propias decisiones médicas y ayudémoslos a hacerlo" (Slack, 1977).

"Los médicos deben dejar de lado la imagen que tienen de ellos mismos de tomar decisiones solos y adoptar, en su lugar, el menos atractivo y más costoso proceso de explorar los resultados más óptimos con el paciente" (Kassirer³).

Podemos decir que existe en la relación médico-paciente una relación de actividad en la cual cada uno adopta un rol y define el modelo. Hasta hace muy pocos años esta relación era casi invariablemente activo-pasiva, adoptando el médico el rol activo, manejando la entrevista, informando y tomando decisiones, prácticamente a su antojo, mientras que el paciente era simplemente el receptor.

Como mencionamos previamente, en los últimos años este cambio se ha sido puesto francamente de manifiesto. En 1956 la aseveración de Hollander parecía revolucionaria y en cierto sentido, herética cuando afirmaban que el viejo modelo de "actividad-pasividad" en la relación médico-paciente estaba siendo reemplazado por un nuevo modelo de "guía-cooperación" y mencionaban también un modelo de "participación mutua".

\section{MODELOS DE LA RELACIÓN MÉDICO-PACIENTE}

En 1992, Ezekiel y Linda Emanuel4 destacaron cuatro modelos de relación médico paciente: paternalista, informativo, interpretativo y deliberativo.

\section{El modelo paternalista}

En este modelo, la relación médico paciente asegura que el paciente sea receptor de las intervenciones que contribuyan a su salud y bienestar. Con este fin, el médico emplea sus conocimientos y habilidades para determinar la situación médica del paciente (diagnóstico), su estadío, la o las pruebas diagnósticas y el tratamiento más adecuado para curarlo o aliviarlo. Luego, el médico presenta al paciente una seleccionada información que le permitirá consentir con la intervención que el médico considera más adecuada. En una situación extrema, el médico informa autoritariamente al paciente el o los procedimientos que se le realizarán. Este modelo asume que existen criterios objetivos para determinar qué es mejor. Por lo tanto, es el médico quien deberá discernir qué es lo más apropiado, limitándose el paciente a consentir y eventualmente, agradecer las decisiones tomadas en su beneficio. El médico actúa como guardián de la salud del paciente. articulando e implementando lo que es mejor para él. Como tal tiene obligaciones que incluyen anteponer los intereses del paciente a los suyos y consultar a otros cuando su conocimiento no sea suficiente. La autonomía del paciente consiste en asentir la determinación médica de qué es lo mejor.

\section{El modelo informativo}

En este modelo, llamado también científico, el objetivo de la interacción médico-paciente es que el médico provea al paciente de toda la información relevante y que éste seleccione o elija las intervenciones médicas que desea. Con este fin, el médico informa al paciente sobre su estado de salud, las posibles intervenciones diagnósticas y terapéuticas, la naturaleza y riesgos o be- 
neficios probables asociados a dichas intervenciones y el grado de incertidumbre al respecto. En un extremo, el paciente podría disponer de toda la información posible y elegir las intervenciones que más le convenzan.

El modelo informativo asume una clara distinción entre hechos y valores. El paciente tiene valores definidos y conocidos pero adolece de hechos. Es obligación del médico proveerlo de los hechos disponibles que le permitirán tomar la decisión más correcta según sus valores. No hay lugar para los valores del médico, o lo que el médico entienda de los valores del paciente o su juicio sobre estos. En el modelo informativo, el médico es un prestador de su idoneidad técnica proveyendo al paciente de los elementos necesarios para ejercer su control. Como experto, debe revelar información confiable, mantener su competencia en el área y consultar a otros cuando su conocimiento o habilidades no sean suficientes. El concepto de autonomía es el control de las decisiones médicas por parte del paciente.

\section{El modelo interpretativo}

En este modelo, la relación médico-paciente apunta a resolver las necesidades del paciente de acuerdo a sus valores y significados. Al igual que en el modelo informativo, aquí el médico provee al paciente de la información sobre la naturaleza de su padecimiento y los riesgos y beneficios de posibles intervenciones, pero además lo ayuda a elucidar y articular sus valores y a determinar qué intervención médica contribuirá mejor a este logro.

En el modelo interpretativo, los valores del paciente no son necesariamente fijos y conocidos, a menudo son elementales y el paciente puede comprenderlos sólo parcialmente o pueden oponerse cuando se aplican a determinadas situaciones. Consecuentemente, el médico, trabajando con el paciente deberá aclarar estos valores y hacerlos coherentes reconstruyendo sus objetivos, aspiraciones, cometidos y caracteres. En su extremo, el médico debe concebir la vida del paciente como un todo narrativo y a partir de ello, relevar sus valores y prioridades para determinar luego qué pruebas y tratamientos serán más apropiados.

El médico no le indica al paciente; es el paciente quien últimamente decide qué valores y cursos de acción encajan mejor en su escala de valores. El médico tampoco juzga los valores del paciente sino que lo ayuda a entenderlos y a aplicarlos en la situación en cuestión.

En el modelo interpretativo, el médico es un consejero o asesor. Por ello sus obligaciones incluyen aquellas enumeradas en el modelo informativo pero también debe comprometer al paciente en el proceso de toma de decisiones. De acuerdo con la concepción de autonomía, el paciente concurre al médico para conocer más claramente quién es y cómo encajan las opciones médicas disponibles en su identidad.

\section{El modelo deliberativo}

En el modelo deliberativo, la interacción médico-paciente apunta a ayudar al paciente a determinar y elegir los mejores valores relacionados con la salud que pueden satisfacer o resolver determinada situación clínica. Con este fin, el médico debe delinear la información de dicha situación y luego, ayudar a elucidar los diferentes valores implícitos en las distintas opciones. Los objetivos del médico incluyen la sugerencia de qué valores relacionados con la situación planteada son los más deseables y a cuáles se debería aspirar. En un extremo, el médico y el paciente deliberan sobre qué tipo de valores relacionados con la salud deberían perseguirse. El médico discute valores solamente relacionados con la salud, es decir, valores que afectan o son afectados por la enfermedad y/o tratamientos del paciente; reconoce que varios elementos morales no están relacionados con la enfermedad o el tratamiento y que por lo tanto no son el objetivo de su relación profesional. Más aún, el objetivo del acto médico no va más allá de la persuasión moral. En esta deliberación, el paciente y el médico juzgan la importancia de los valores relacionados con la salud. En el modelo deliberativo, el médico actúa como un maestro o amigo, dialogando con el paciente sobre qué curso de acción sería el mejor. No sólo considerando lo que el paciente podría hacer sino que, conociéndolo y deseando lo que es mejor, le indica qué debería hacer, qué decisión concerniente a su tratamiento sería ponderable o deseable. La concepción de autonomía del paciente sería el auto-desarrollo moral; el paciente es alentado no solo a seguir preferencias sino a considerar, a través del diálogo, valores alternativos relacionados con la salud, su deseabilidad e implicancias en el tratamiento.

Estos diferentes modelos implican variaciones en la actitud más o menos pasiva del paciente y del médico y, en consecuencia, diferentes grados de autonomía y relevancia de los valores del paciente y de la influencia del médico en las decisiones de éste. ¿Un médico utiliza siempre el mismo modelo con todos sus pacientes? ¿Es más deseable un modelo que otro? ¿Pueden convivir más de un modelo en una misma relación médico-paciente? Es claro que, en las distintas circunstancias clínicas, los modelos apropiados pueden variar más aún, en tiempos y situaciones diferentes los cuatro modelos pueden coexistir. Por otro lado, determinadas situaciones imponen ciertos modelos: en una emergencia clínica, en la que el tiempo es fundamental, el médico tomará decisiones por su cuenta adoptando el modelo paternalista, en consultas de guardia ambulatoria, en las que el médico verá probablemente por única vez al paciente, prevalecerá el modelo informativo y en algunas circunstancias el modelo interpretativo se impone sobre el modelo deliberativo, que se reserva para relaciones médico-paciente establecidas y extendidas en el tiempo.

Probablemente el modelo más indicado y reconocido como ideal sea el deliberativo, por varias razones:

1. Es el modelo que más condice con el concepto de autonomía de los pacientes. Autonomía que, en sentido amplio y abarcativo, va mucho más allá de la concepción de que el paciente pueda elegir. La autonomía verdadera es aquella que permite al paciente determinar críticamente sus valores y preferencias, afirmar estos valores en base a reflexiones y decidir e iniciar las acciones que ellos justifiquen.

2. El médico ideal para las sociedades evolucionadas no es sólo aquel que se limita a saber y comunicar información fáctica y procede a implementar intervenciones médicas. El médico ideal es aquel que integra la información y los valores relevantes para luego recomendar y discutir las intervenciones más apropiadas para el caso.

3. Aunque en la práctica, el médico deliberativo puede incurrir errónea o temporariamente en actitudes paternalistas, el modelo deliberativo no es un paternalismo enmascarado. A semejanza del maestro ideal, el médico deliberativo intenta persuadir al paciente de ciertos valores y no imponerlos.

4. Los valores y actitudes del médico también son importantes para el paciente e influyen directamente en la elección de su médico: algunos pacientes eligen médicos muy intervencionistas que, estando en salud, realizan múltiples pruebas diagnósticas y lo citan frecuentemente al consultorio; otros pacientes eligen médicos que enfatizan en aspectos de la calidad de vida y realizan sólo prácticas mínimas y validadas. 
5. Además de ayudar a recomendar terapéuticas de acuerdo a vaIores y preferencias, en el modelo deliberativo el médico deberá promover aquellos valores relacionados con la salud. El sexo seguro, el no consumo de alcohol, las prácticas de seguridad vial son actitudes relacionadas con valores que el médico puede promover desde su rol en la relación médico-paciente.

6. La falta de actitudes, entrenamiento y conocimientos por parte de los médicos para articular los valores que determinan sus recomendaciones es consecuencia, en parte, de la tendencia a la especialización y a la actitud de evitar la discusión de valores con los pacientes.

\section{Dr. Carlos García [ Director de la Red de Atención Médica del Hospital Italiano de Buenos Aires ]}

\section{Bibliografía}

1. Cassell E., Talking With Patients, volume I: The Theory of Doctor-Patient Communication (Cambridge, Mass: The MIT Press; 1985) citado en Laine C, Davidoff F Patient-centered medicine: a professional evolution. JAMA.1996;275:152-156.

2. Oken O What to tell cancer patients. JAMA 1961;175:1120-1128

3. Kassirer J. Adding insult to injury: usurping patients' prerogatives. N Engl J Med. 1983;308:898-901

4. Emanuel E, Emanuel L. Four models of the doctor-patient relationship. JAMA. 1992;267:2221-2226

\section{¿Cómo citar Evidencia en Atención Primaria?}

1. Cita del resumen estructurado o glosario, sin autoría específica de ningún miembro del Comité Editorial: Estudio de prevalencia de aneurismas de aorta abdominal y su asociación con factores de riesgo (resumen) Evidencia en Atención Primaria. 1997 Octubre- Diciembre Vol O Nro 0: 19. Resumen de: Lederle F, Johnson G, et al. Prevalence and associations of abdominal aortic aneurisms detected through screening Ann. Intern. Med.1997; 126:441-449.

2. Cita del comentario del artículo: Granel A. Comentario de Estudio de prevalencia de aneurismas de aorta abdominal y su asociación con factores de riesgo Evidencia en Atención Primaria. 1997 Octubre-Diciembre Vol 0 Nro 0: 19. Comentado de: Lederle F, Johnson G, et al. Prevalence and associations of abdominal aortic aneurisms detected through screening Ann. Intern. Med. 1997; 126:441-449.

3. Cita de Editorial, Actualización: Rubinstein F. Editorial: Evidencia en atención primaria: ¿es necesaria?. Evidencia en Atención Primaria. 1997 Octubre-Diciembre Vol 0 Nro 0:1-2.

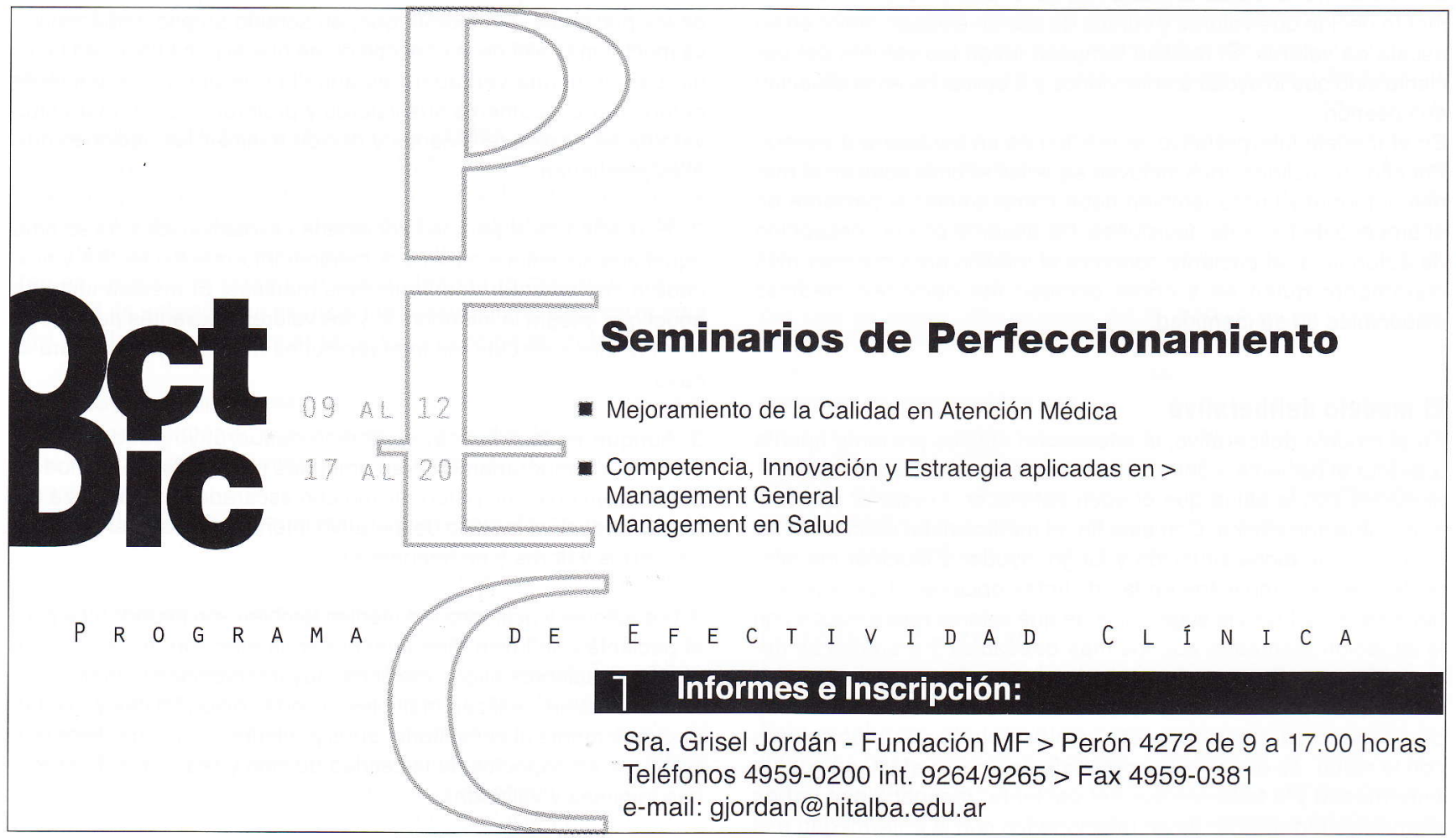

